\title{
Prevalence of hypertension in Type 1 (insulin-dependent) diabetes mellitus
}

\author{
K. Nørgaard ${ }^{1}$, B.Feldt-Rasmussen ${ }^{1}$, K. Borch-Johnsen ${ }^{1}$, H. Sælan ${ }^{2}$ and T. Deckert ${ }^{1}$ \\ ${ }^{1}$ Steno Memorial Hospital, Gentofte, and ${ }^{2}$ Institute for Social Medicine, University of Copenhagen, Denmark
}

\begin{abstract}
Summary. The prevalence of hypertension in a representative sample $(n=10202)$ of the Danish general population aged $16-59$ years was assessed to $4.4 \%$ based on three blood pressure readings. In Type 1 (insulin-dependent) diabetic patients of similar age $(n=1703)$ the prevalence was determined in a similar way to $14.7 \%(p<0.00001)$. The excess prevalence in Type 1 diabetic patients was due to hypertension in patients with incipient and clinical nephropathy as the prevalence of hypertension among diabetic patients with normal urinary albumin excretion (essential hypertension) was $3.9 \%$, similar to that observed in the general population. The patients with Type 1 diabetes and essential hypertension had higher systolic $(146 \pm 19$ vs $133 \pm 18 \mathrm{~mm} \mathrm{Hg}, p<0.00001)$ and diastolic blood pressure $(87 \pm 12$ vs $79 \pm 7 \mathrm{mmHg}$, $p<0.00001$ ), but less changes in the eye background than patients with incipient nephropathy (urinary albumin excretion
\end{abstract}

$30-300 \mathrm{mg} / 24 \mathrm{~h})(p<0.03)$, indicating that the two groups were also different with respect to other microangiopathic lesions. Patients with essential hypertension were defined as having a normal urinary albumin excretion before and during antihypertensive treatment (if any). They were followedup for a 58 (6-234) month period. We confirmed that hypertension is more common among Type 1 diabetic patients than in the general population and found the prevalence of essential hypertension similar in Type 1 diabetic patients to the non-diabetic population. This supports our hypothesis that hypertension is very unlikely to be the cause of diabetic nephropathy.

Key words: Prevalence, essential hypertension, blood pressure, Type 1 (insulin-dependent) diabetes mellitus, retinopathy, nephropathy.
The prevalence of hypertension is often reported as high in patients with Type 1 (insulin-dependent) as well as in Type 2 (non-insulin-dependent) diabetes compared with non-diabetic subjects [1-7]. It is well known that the presence of hypertension is important for the progression of diabetic nephropathy $[8,9]$, but it is debatable whether elevated blood pressure also plays a pathogenic role in the development of nephropathy in Type 1 diabetes. Thus, in a prospective study blood pressure remained stable at the time when a significant increase in urinary albumin excretion (UAE) was registered [10] and in a cross-sectional study blood pressure was not significantly elevated before the UAE exceeded $100 \mathrm{mg} / 24 \mathrm{~h}$ [11]. Our hypothesis is that the rise in blood pressure in Type 1 diabetic patients with renal complications is a consequence of, and not a cause of nephropathy [11]. If this is the case, it should be possible to identify a population of Type 1 diabetic patients with arterial hypertension and no signs of incipient nephropathy (normal UAE) i. e. essential hypertension. In this population the risk of developing diabetic nephropathy should not exceed the risk that normotensive diabetic patients have of developing this complication. Therefore, we expect the prevalence of essential hypertension to be similar to that of the general population or reduced by less than $30 \%$ which is the cumulative incidence of diabetic nephropathy [12].
The aim of the present study was (a) to determine the overall prevalence of hypertension in Type 1 diabetic patients with juvenile onset and (b) to assess the prevalence of essential hypertension in the same population and (c) to compare the results with the prevalence of hypertension in the Danish general population.

\section{Subjects and methods}

\section{Type 1 diabetic patients}

All Type 1 diabetic patients aged $16-59$ years with onset of diabetes before the age of 35 years regularly attending the out-patient clinic (twice a year or more) at the Steno Memorial Hospital in 1988 were identified. Retrospective data from the hospital records were collected. Blood pressure in our clinic is always measured by the doctors by a standard sphygmomanometer after 5 min rest in the sitting position and registered to the nearest $5 \mathrm{~mm} \mathrm{Hg}$. The status of the retina was classified as normal, background retinopathy, proliferative retinopathy or blindness based on the last ophthalmoscopic examination through dilated pupils. Urinary albumin concentration in a 24-h urine collection was measured by an ELISA-assay [13]. If the UAE was above $30 \mathrm{mg} / 24 \mathrm{~h}$ the urine was cultured for bacteria routinely in order to exclude urinary tract infection. Based on the last three blood pressure measurements and the last three UAE measurements, the following groups of patients were established: 


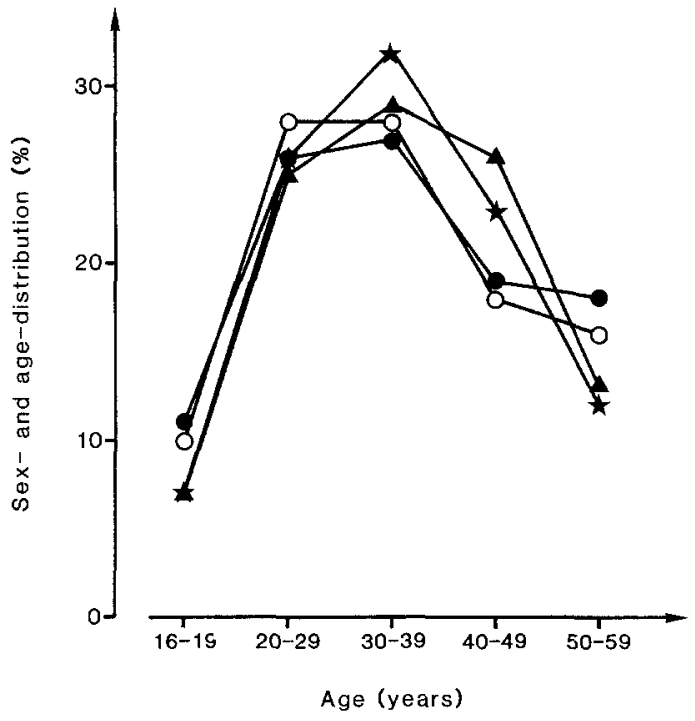

Fig. 1. Sex- and age-distribution of the general population and the Type 1 (insulin-dependent) diabetic patients. - non-diabetic males, $\mathrm{O}_{-} \mathrm{O}$ : non-diabetic females; $\boldsymbol{\wedge}-\mathbf{\wedge}$ : Type 1 diabetic males, *-*: Type 1 diabetic females

Group 1. Patients with hypertension and clinical or incipient nephropathy. These patients fulfilled the following criteria: (a) Ongoing antihypertensive treatment or systolic blood pressure $\geq 160 \mathrm{~mm} \mathrm{Hg}$ and/or diastolic blood pressure $\geq 95 \mathrm{~mm} \mathrm{Hg}$ at all three measurements. (b) A UAE in at least two of the last three collections $\geq 30 \mathrm{mg} / 24 \mathrm{~h}$ or $\geq 30 \mathrm{mg} / 24 \mathrm{~h}$ at the start of antihypertensive treatment. Patients with non-diabetic renal diseases were excluded.

Group 2. Patients with hypertension and normoalbuminuria (essential hypertension). (a) Ongoing antihypertensive treatment or systolic blood pressure $\geq 160 \mathrm{mmHg}$ and/or diastolic blood pressure $\geq 95 \mathrm{~mm} \mathrm{Hg}$ in the last three measurements. (b) At onset of antihypertensive treatment UAE was below $30 \mathrm{mg} / 24 \mathrm{~h}$ or no proteinuria was assessed by Albym-Test, (Boehringer Mannheim, FRG, (sensitivity level: $60 \mathrm{mg}$ albumin/l)). (c) Median value of the last three UAE measurements below $30 \mathrm{mg} / 24 \mathrm{~h}$.

At start of antihypertensive treatment blood pressure as well as the calender date were registered.

Table 1. Hypertension in the Danish non-diabetic population $(n=10202)$

\begin{tabular}{lcccccc}
\hline Age (years) & $16-19$ & $20-29$ & $30-39$ & $40-49$ & $50-59$ & All \\
\hline Males & 1 & 17 & 40 & 57 & 94 & 209 \\
$(\%)$ & $(0.2)$ & $(1.3)$ & $(3.1)$ & $(6.2)$ & $(11.0)$ & $(4.3)$ \\
Females & 2 & 21 & 25 & 73 & 114 & 235 \\
$(\%)$ & $(0.4)$ & $(1.4)$ & $(1.7)$ & $(7.6)$ & $(13.1)$ & $(4.4)$ \\
\hline
\end{tabular}

Results shown as $n$, prevalence in (\%)

\section{General population}

In the community of Næstved (43000 inhabitants) in Denmark, all patients in the age group $16-59$ years $(n=11050)$ registered and attending five randomly selected medical centres (general practitioners) were invited to a screening for hypertension [14] Danish citizens are all registered with a general practitioner, whom they see in case of illness. Blood pressure was measured with a standard sphygmomanometer only once if normal. If blood pressure was elevated two additional measurements were performed with at least a one week interval. Hypertension was defined as ongoing antihypertensive treatment or systolic blood pressure $\geq 160$ and/or diastolic blood pressure $\geq 95 \mathrm{~mm} \mathrm{Hg}$ in three measurements.

\section{Statistical analysis}

The comparisons of the age- and sex-distribution for the diabetic and non-diabetic population and the status of the retina were done by a two sample rank sum test on the $\mathrm{N} \times 2$ table, were $\mathrm{N}$ represents an ordinal scale.

In comparing the prevalence rates in the diabetic population with the Næstved-population, chi-square tests where performed seperately for each age- and sex-specific group.

\section{Results}

The number of Type 1 diabetic patients with diabetes onset before the age of 35 years in the age-group 1659 years attending the Steno Memorial Hospital was 1703. In the community of Næstved 10202 persons aged 1659 years participated in the screening corresponding to a response rate of $92.3 \%$ of the population selected for this study. With respect to sex- and age-distribution the diabetic population was comparable to the general population in Næstved (Fig. 1).

In the general population the overall prevalence of hypertension was $4.4 \%$ and was similar among males and females in all age-groups. The prevalence increased with age in both sexes (Table 1).

In our population of Type 1 diabetic patients the overall prevalence of hypertension was $14.7 \%(p<0.00001)$, increasing with age in both sexes (Table 2). In the agegroup 30-39 years the prevalence was higher among females ( $p<0.001$, Table 2$)$, in the other age-groups the prevalence was similar in males and females.

The excess prevalence of hypertension in all diabetic age-groups above 20 years as compared to the general population was due to hypertension in patients with incipient or clinical diabetic nephropathy (Fig.2) since the

Table 2. Prevalence of hypertension in Type 1 (insulin-dependent) diabetic patients with different levels of urinary albumin excretion

\begin{tabular}{|c|c|c|c|c|c|c|c|}
\hline Age (years) & & 16-19 & $20-29$ & $30-39$ & $40-49$ & $50-59$ & All \\
\hline $\begin{array}{l}\text { Normoalbuminuria } \\
(<30 \mathrm{mg} / 24 \mathrm{~h})\end{array}$ & $\begin{array}{l}\text { Males }(n=722)(\%) \\
\text { Females }(n=579)(\%)\end{array}$ & $\begin{array}{l}0.0 \\
0.0\end{array}$ & $\begin{array}{l}1.6 \\
0.7\end{array}$ & $\begin{array}{l}3.1 \\
2.2\end{array}$ & $\begin{array}{l}5.6 \\
8.6\end{array}$ & $\begin{array}{r}7.5 \\
14.1\end{array}$ & $\begin{array}{l}3.6 \\
4.3\end{array}$ \\
\hline $\begin{array}{l}\text { Microalbuminuria } \\
(30-300 \mathrm{mg} / 24 \mathrm{~h})\end{array}$ & $\begin{array}{l}\text { Males }(n=134)(\%) \\
\text { Females }(n=95)(\%)\end{array}$ & $\begin{array}{l}0.0 \\
0.0\end{array}$ & $\begin{array}{l}9.4 \\
7.4\end{array}$ & $\begin{array}{l}15.4 \\
26.7\end{array}$ & $\begin{array}{l}39.4 \\
33.3\end{array}$ & $\begin{array}{l}43.3 \\
33.3\end{array}$ & $\begin{array}{l}24.6 \\
23.1\end{array}$ \\
\hline $\begin{array}{l}\text { Macroalbuminuria } \\
(>300 \mathrm{mg} / 24 \mathrm{~h})\end{array}$ & $\begin{array}{l}\text { Males }(n=83)(\%) \\
\text { Females }(n=90)(\%)\end{array}$ & $\begin{array}{r}0.0 \\
50.0\end{array}$ & $\begin{array}{l}71.4 \\
78.3\end{array}$ & $\begin{array}{l}77.8 \\
86.5\end{array}$ & $\begin{array}{l}75.9^{\mathrm{b}} \\
100.0\end{array}$ & $\begin{array}{r}100.0 \\
80.0\end{array}$ & $\begin{array}{l}79.5 \\
85.6\end{array}$ \\
\hline All patients & $\begin{array}{l}\text { Males }(n=939)(\%) \\
\text { Females }(n=764)(\%)\end{array}$ & $\begin{array}{l}0.0 \\
2.0 \\
\end{array}$ & $\begin{array}{r}6.8 \\
10.6 \\
\end{array}$ & $\begin{array}{l}11.6^{\mathrm{a}} \\
17.9 \\
\end{array}$ & $\begin{array}{l}18.7 \\
20.7 \\
\end{array}$ & $\begin{array}{l}26.0 \\
24.7 \\
\end{array}$ & $\begin{array}{l}13.3^{\mathrm{b}} \\
16.2 \\
\end{array}$ \\
\hline
\end{tabular}




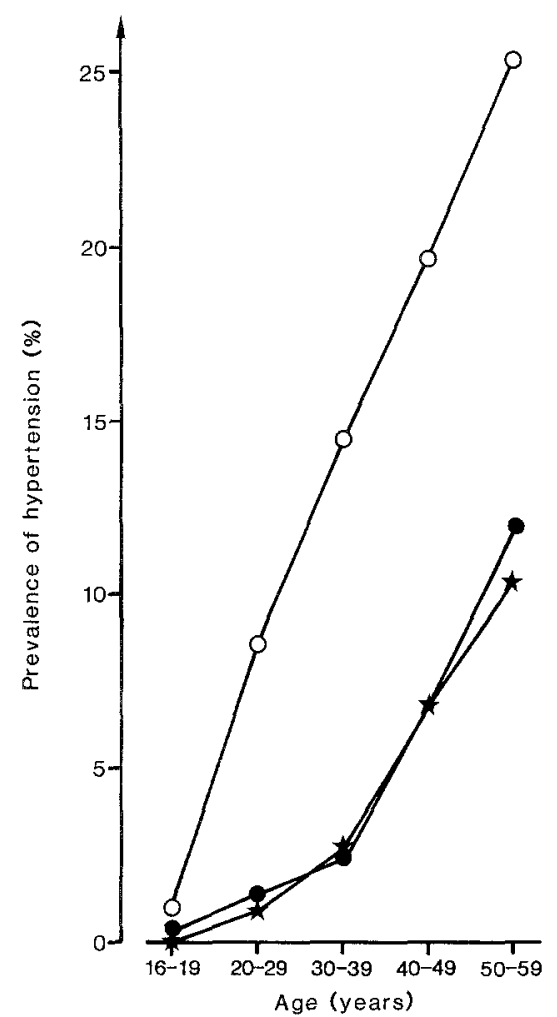

Fig. 2. Prevalence of hypertension in all Type 1 (insulin-dependent) diabetic patients $(n=1703),(0-O)$, in the Danish general population $(n=10202),(-\bullet)$ and in the normoalbuminuric diabetic patients $(n=1301),(*-*)$

prevalence of hypertension in Type 1 diabetic patients with normoalbuminuria was similar to the prevalence in the Danish general population ( $3.9 \%$ vs $4.4 \%$, NS).

Essential hypertension, defined as hypertension in patients with persistently normal UAE, was observed in 51 diabetic patients ( 26 male/ 25 female). Forty-five of whom received antihypertensive medication. At the time when antihypertensive treatment was started the systolic blood pressure was $163 \pm 18 \mathrm{~mm} \mathrm{Hg}$ and the diastolic blood pressure $102 \pm 9 \mathrm{~mm} \mathrm{Hg}$. All had Albym-Test negative urine when antihypertensive treatment was initiated and 17 patients had their UAE measured before treatment. UAE was 12 (4-30) $\mathrm{mg} / 24 \mathrm{~h}$, (median and range). They had been treated for 58 (6-234) months and were $45 \pm 9$ years of age with a diabetes duration of $24 \pm 13$ years. The actual blood pressure was systolic $146 \pm 19 \mathrm{~mm} \mathrm{Hg}$ and diastolic $87 \pm 12 \mathrm{~mm} \mathrm{Hg}$. Six patients fulfilling the criteria for hypertension but still untreated had a median UAE of $13(5-20) \mathrm{mg} / 24 \mathrm{~h}$.

The prevalence of incipient nephropathy, i.e. a UAE of $30-300 \mathrm{mg} / 24 \mathrm{~h}$ (microalbuminuria), in the diabetic population was $14 \%$ in males and $12 \%$ in females (NS), and the prevalence of clinical nephropathy, i.e. UAE above $300 \mathrm{mg} / 24 \mathrm{~h}$, was $9 \%$ and $12 \%$, respectively (NS). Hypertension was seen in $25 \%$ of the males and in $23 \%$ of the females with microalbuminuria, and in $80 \%$ and $86 \%$, respectively of patients with clinical diabetic nephropathy.

The current age of patients with normoalbuminuria ( $35 \pm 11$ years) was lower than the age of patients with incipient nephropathy $(37 \pm 12$ years, $p<0.05)$ and clinical nephropathy ( $38 \pm 10$ years, $p<0.05$ ). The diabetes duration was $17 \pm 11$ years, $21 \pm 10$ years and $25 \pm 9$ years, respectively, and then increasing with the albuminuria levels $(p<0.001)$.

The retina was significantly less affected in the diabetic patients with essential hypertension than in patients with incipient nephropathy $(p<0.03)$ and in patients with clinical nephropathy $(p<0.00001$, Table 3$)$. Both systolic and diastolic blood pressure was significantly lower in patients with incipient nephropathy as compared to patients with essential hypertension $(p<0.00001$ and $p<0.00001$, respectively). Blood pressure was similar in patients with essential hypertension and clinical nephropathy.

\section{Discussion}

This study has shown that the increased prevalence of hypertension in Type 1 diabetic patients compared with a non-diabetic population can be explained by the presence of hypertension in patients with incipient or overt diabetic nephropathy. Furthermore, the study demonstrated that the prevalence of essential hypertension is similar in a population of Type 1 diabetic patients and in the general population.

The Type 1 diabetic population at the Steno Memorial Hospital was comparable to the general population in the Næstved community with respect to age- and sex-distribution. In the two populations we applied the same methods and definitions for the diagnosis of hypertension. Data collections in the two populations were performed within the same five year period.

We have defined hypertension as being essential if UAE was persistently below $30 \mathrm{mg} / 24 \mathrm{~h}$ and if microalbuminuria and/or proteinuria had not been demonstrated before the start of antihypertensive medication. Two possibilities for miscalculating the prevalence of essential hypertension exist. An overestimation can take place if some of these patients have early diabetic nephropathy with normalized UAE after antihypertensive therapy. However, this risk is small because the hypertension of diabetic nephropathy seems to appear after the onset of

Table 3. Urinary albumin excretion (UAE), blood pressure and retinal changes in Type 1 (insulin-dependent) diabetic patients with essential hypertension, incipient nephropathy and clinical nephropathy. Medians and ranges are given for UAE, mean $\pm 1 \mathrm{SD}$ for blood pressure. $95 \%$ confidence interval are given for the retina

\begin{tabular}{lccl}
\hline & $\begin{array}{l}\text { Essential } \\
\text { hypertension } \\
n=51\end{array}$ & $\begin{array}{l}\text { Incipient } \\
\text { nephropathy } \\
n=229\end{array}$ & $\begin{array}{l}\text { Clinical } \\
\text { nephropathy } \\
n=173\end{array}$ \\
\hline UAE: mg/24 h & $10(4-29)$ & $77(31-295)$ & $832(300-8802)$ \\
$\begin{array}{l}\text { Blood pressure (mm Hg) } \\
\text { Systolic }\end{array}$ & $146 \pm 19$ & $133 \pm 18^{\mathrm{a}}$ & $144 \pm 19$ \\
Diastolic & $87 \pm 12$ & $79 \pm 7^{\mathrm{a}}$ & $86 \pm 8$ \\
$\begin{array}{l}\text { Retina examination: } \\
\text { \% Normal }\end{array}$ & $46(32-59)$ & $31(25-37)^{\mathrm{b}}$ & $6(3-10)^{\mathrm{a}}$ \\
\% Simplex retinopathy & $37(24-50)$ & $41(35-48)^{\mathrm{b}}$ & $27(21-34)^{\mathrm{a}}$ \\
\% Proliferative retinopathy & $17(9-31)$ & $24(19-30)^{\mathrm{b}}$ & $45(38-53)^{\mathrm{a}}$ \\
$\%$ Blind & $0(0-6)$ & $4(2-7)^{\mathrm{b}}$ & $22(16-29)^{\mathrm{a}}$ \\
\hline
\end{tabular}

Comparisons are with values for patients with essential hypertension: ${ }^{\mathrm{a}} p<0.00001 ;{ }^{\mathrm{b}} p<0.03$ 
microalbuminuria [10] and a positive Albym-Test or periods with UAE $>30 \mathrm{mg} / 24 \mathrm{~h}$ were never seen in our 51 patients during the observation period of about six years. Furthermore, the effect of antihypertensive treatment on UAE in patients with persistent microalbuminuria is small [15] and only a minority of such patients will during several years of antihypertensive treatment demonstrate persistent normoalbuminuria [16]. Also the blood pressure of patients with essential hypertension was significantly higher $(p<0.00001)$ than in patients with incipient nephropathy and in spite of this the latter group had a significantly higher UAE of $77 \mathrm{mg} / 24 \mathrm{~h}(p<0.00001)$. Lastly, the patients with essential hypertension had significantly fewer retinal changes than patients with incipient nephropathy (Table 3 ) indicating that the two groups are also different with respect to other microangiopathic lesions. An underestimation of the prevalence of essential hypertension takes place if some of those classified as patients with incipient nephropathy are essential hypertensives with an elevated UAE. Non-diabetic patients with essential hypertension may have an elevated UAE [17] especially when blood pressure is high, but Type 1 diabetic patients with renal impairment will have a much higher UAE, at a given blood pressure, compared with patients with essential hypertension [18].

The prevalence of hypertension in the Danish general population as well as in our Type 1 diabetic population is lower than that found in the United States [4, 19], probably due to differences in diagnostic criteria. In our general population the prevalence of hypertension was threefold higher if the diagnosis was based on one blood pressure measurement only as was the case in the American studies $[4,19]$ (In the Framingham study two measurements were made but at the same day of examination). An Irish group has recently found exactly the same prevalence of hypertension in Type 1 patients as we have, in spite of different methods and definitions [5]. They measured one blood pressure only and defined hypertension as ongoing antihypertensive treatment and/or systolic blood pressure as well as diastolic pressure exceeding the 90th percentile for age and sex. Parving and coworkers [20] found a higher prevalence in normoalbuminuric patients $(19 \%)$, but they excluded patients with a diabetes duration of less than five years, included all age groups and used only one urine sample and one blood pressure reading for classifying patients.

The prevalence of hypertension was highest among females. Christlieb et al. also found hypertension more often among females with Type 1 diabetes [4], in contrast to the observations of Kelleher et al. [5].

The prevalence of renal complications in our study was lower than those found in another Danish study [20] possibly due to differences in methods as mentioned for the difference in prevalence of hypertension.

In summary, we confirmed that the overall prevalence of hypertension in Type 1 diabetic patients is much higher than in the general population. The prevalence of essential hypertension in Type 1 diabetic patients with normoalbuminuria was similar to that of the general population. This observation is new and supports that hypertension is very unlikely to be the cause of diabetic nephropathy.

\section{References}

1. Major SG (1929) Blood pressure in diabetes mellitus: a statistical study. Arch Intern Med 44: 797-812

2. Adams S (1929) A study of the blood pressure of patients with diabetes mellitus. Am J Med Soc 177: 195-201

3. Pell S, D'Alonzo CA (1967) Some aspects of hypertension in diabetes mellitus. JAMA 202: 104-110

4. Christlieb AR, Warram JH, Krolewski AS, Busick EJ, Ganda OP, Asmal AC, Soeldner JS, Bradley RF (1981) Hypertension: the major risk factor in juvenile-onset insulin-dependent diabetics. Diabetes 30 [Suppl 2]: 90--96

5. Kelleher C, Kingston SM, Barry DG, Cole MM, Ferris JB, Grealy G, Joyce C, O'Sullivann DJ (1988) Hypertension in diabetic clinic patients and their siblings. Diabetologia 31: 76-81

6. Simonsen DC (1988) Etiology and prevalence of hypertension in diabetic patients. Diabetes Care 11:821-827

7. Sprafka JM, Bender AP, Jagger HG (1988) Prevalence of hypertension and associated risk factors among diabetic individuals. The Three-City study. Diabetes Care 11: 17-22

8. Parving HH, Andersen AR, Schmidt UM, Svendsen PA (1983) Early aggresive antihypertensive treatment reduces rate of decline in kidney function in diabetic nephropathy. Lancet I: 11751179

9. Mogensen CE (1982) Long-term antihypertensive treatment inhibiting progression of diabetic nephropathy. Br Med J 285: 685 688

10. Mathiesen ER, Rønn B, Jensen T, Storm B and Deckert T (1988) Microalbuminuria precedes elevation in blood pressure in diabetic nephropathy. Diabetologia 31: 519 (Abstract)

11. Deckert T, Feldt-Rasmussen B, Borch-Johnsen K, Jensen T, Kofoed-Enevoldsen A (1989) Albuminuria reflects widespread vascular damage. The Steno hypothesis. Diabetologia 32: 219-226

12. Kofoed-Enevoldsen A, Borch-Johnsen K, Kreiner S, Deckert T (1987) Declining incidence of persistent proteinuria in Type 1 (insulin-dependent) diabetic patients in Denmark. Diabetes 36: 205-209

13. Feldt-Rasmussen B, Dinesen B, Deckert M (1985) Enzyme immunoassay- an improved determination of urinary albumin in diabetics with incipient nephropathy. Scand J Clin Lab Invest 45: 539-544

14. Sælan H, Krasnik A, Kempinski R (1979) Community medicine in the primary health sector. II. The distribution of blood-pressure as a risk factor, a community diagnosis. Ugeskr Læg 141:45-51

15. Marre M, Leblane H, Suarez L, Guyenne T-T, Menard J, Passa P (1987) Converting enzyme inhibition and kidney function in normotensive diabetic patients with persistent microalbuminuria. Br Med J 294: 1448-1452

16. Christensen CK, Mogensen CE (1987) Antihypertensive treatment: long-term reversal of progression of albuminuria in incipient diabetic nephropathy. A longitudinal study of renal function. J Diab Compl 1: 45-52

17. Parving H-H, Gyntelberg F (1973) Transcapillary escape rate of albumin and plasma volume in essential hypertension. Cir Res 32: $643-651$

18. Christensen CK, Krusell, Mogensen CE (1987) Increased blood pressure in diabetes: essential hypertension or diabetic nephropathy? Scand J Clin Lab Invest 47: 363-370

19. Gordon T, Shurtleff D (1974) Means at each examination and interexamination variation of specified characteristics: Framingham Study Exam 1 to 10. NIH Publication no. 74-478

20. Parving H-H, Hommel E, Mathiesen E, Skøtt P, Edsberg B, Bahnsen M, Lauritzen M, Hougaard P, Lauritzen E (1988) Prevalence of microalbuminuria, arterial hypertension, retinopathy and neuropathy in patients with insulin dependent diabetes. $\mathrm{Br}$ Med J 296: 156-160

Received: 9 October 1989

and in revised form: 6 February 1990

Dr. K. Nørgaard

Steno Memorial Hospital

DK-2820 Gentofte, Denmark 